\title{
CINÉTICA DE ADSORÇÃO DE AZUL DE METILENO POR MOLIBDATO DE ESTRÔNCIO
}

\author{
L. Y. K. S. UCHÔA ${ }^{1}$, V. D. S. FREITAS ${ }^{1}$, M. F. T. MENEZES ${ }^{1}$, A. L. LOPES - \\ MORIYAMA $^{1}$ e C. P. DE SOUZA ${ }^{1}$
}

${ }^{1}$ Universidade Federal do Rio Grande do Norte, Departamento de Engenharia Química laurenyo@gmail.com.br

\begin{abstract}
RESUMO - Com o crescimento industrial e, consequentemente, o aumento da preocupação com o descarte e tratamento adequado de resíduos, o estudo de novos materiais e técnicas vem, como necessidade, para realizar o tratamento de efluentes de maneira cada vez mais eficaz e com custos reduzidos. Com o objetivo de estudar a cinética de adsorção, foram feitos ensaios de adsorção do azul de metileno por molibdato de estrôncio dopado com cobre no sítio A de sua estrutura $\left(\mathrm{AMoO}_{4}, \mathrm{~A}=0,8\right.$ estrôncio $+0,2$ cobre $)$ utilizando soluções de corante em duas concentrações (40 e 50 pmm). Pôde-se observar que a mudança da concentração das soluções não causa mudança significativa na quantidade de corante removida, que o material em análise realiza pouca adsorção nas duas condições e que a cinética de adsorção do material é descrita pelo modelo de difusão intrapartícula.
\end{abstract}

\section{INTRODUÇÃO}

A crescente industrialização mundial trouxe consigo um aumento na quantidade de resíduos gerados, muitas vezes descartados de maneira incorreta no meio ambiente. Os avanços tecnológicos, o aumento da atenção voltada à conservação ambiental e uma crescente fiscalização levam à busca de novos materiais e métodos para o tratamento dos efluentes (Silva, 2016). O setor têxtil é extremamente afetado por essa realidade, uma vez que, segundo Santos e Fernandes (2012), em todas as fases da produção têxtil é possível verificar a quantidade de resíduos gerados e de impactos que isso causa ao meio ambiente.

Um dos principais impactos ambientais causados pela indústria têxtil é relacionado com a fase de tingimento dos tecidos. Sabe-se que a água é um elemento essencial para a realização dessa parte do processo e a utilização de substância, como os corantes, causa modificações na qualidade da água (Santos, 1997). Processos adsortivos estão sendo cada vez mais utilizados para o tratamento desse tipo de efluentes, uma vez que, por acontecer de maneira espontânea, é uma alternativa barata para tal utilização.

A adsorção pode ser definida, de maneira simplificada, como o processo em que moléculas presentes em um fluido, que pode ser líquido ou gasoso, concentram-se sobre uma superfície sólida. O processo está intimamente ligado à tensão superficial das soluções, uma vez que, a adsorção ocorre quando existe uma superfície de contato entre um sólido e um líquido ou gás. 
Dessa forma, como a adsorção é um fenômeno, em sua maioria, de superfície, é necessário que, para ser classificado como um adsorvente com alta capacidade adsortiva, o material tenha alta área superficial específica, ou seja, possua estrutura porosa. (Filho, 2012)

O material estudado é classificado como um molibdato, classe de compostos inorgânicos de interesse no estudo de novas tecnologias. Estudos indicam que essa classe de compostos possui propriedades ópticas e fotocatalíticas, além da fotoluminescência. A dopagem de materiais é uma importante estratégia para melhorar ou potencializar as propriedades de um catalisador (Dutra, 2016), podendo melhorar a eficiência de um molibdato em uma de suas utilizações. O composto em estudo é o molibdato de estrôncio, que pertence à família das scheelitas, por cristalizar em uma estrutura tetragonal (Silva, 2016), dopado com cobre no sítio $\mathrm{A}$ de sua estrutura $\left(\mathrm{AMoO}_{4}, \mathrm{~A}=0,8\right.$ estrôncio + 0,2 cobre).

Ao longo do trabalho, estudou-se a capacidade adsortiva desse material com corante azul de metileno, já que é amplamente utilizado para o tingimento de materiais como algodão, papel, couro e fibras sintéticas (Dutra, 2016). Diante do atual cenário industrial e da necessidade de cuidado com o meio ambiente, este trabalho tem como intuito analisar a capacidade desse material em adsorver o contaminante da indústria têxtil já citado.

\section{MATERIAIS E MÉTODOS}

\subsection{Materiais}

Molibdato de estrôncio $\left(\mathrm{SrMoO}_{4}\right)$ foi produzido através da rota de complexação EDTACitrato, dopado em $20 \%$ por cobre. Em um procedimento comum, esse material passa pela pré-calcinação, calcinação, lavagem e secagem. Esses processos consistiram em, respectivamente, tratamento térmico do sólido à $230^{\circ} \mathrm{C}$, procedimento similar à $650^{\circ} \mathrm{C}$, lavagem com água controlando $\mathrm{pH}$ e condutividade, e secagem em estufa à $80^{\circ} \mathrm{C}$. O pó assim produzido foi caracterizado por difração de raios-X no equipamento de marca Bruker e modelo D8 Advance.

\subsection{Estudo da cinética de adsorção}

Os ensaios de adsorção foram realizados em um recipiente de vidro com agitação constante, e conectado a um banho termostático que manteve a temperatura entorno de $31^{\circ} \mathrm{C}$. Devido às propriedades fotocatalíticas do material, o recipiente permaneceu no interior de uma caixa de madeira forrada com papel alumínio, sem contato com a luz ambiente.

Dentro do recipiente de vidro colocou-se $500 \mathrm{~mL}$ de solução de $50 \mathrm{ppm}$ de azul de metileno. Utilizou-se a massa de $65 \mathrm{mg}$ do catalisador para cada ensaio. Com o início dos ensaios, amostras de $6 \mathrm{~mL}$ da solução foram retiradas a cada 10 minutos e tiveram sua temperatura medida. Após 100 minutos o experimento foi encerrado e as amostras foram diluídas para serem analisadas em espectrofotômetro de marca VARIAN e modelo Cary 50 Conc. A partir destas medidas, obtiveram-se valores da concentração da solução de azul de metileno em função do tempo. O procedimento foi repetido para $500 \mathrm{~mL}$ de solução de 40 ppm, estabelecendo uma nova condição de concentração do corante. 


\section{RESULTADOS}

Para avaliar o desempenho do material durante o processo de adsorção os valores de absorbância fornecidos pelo espectrofotômetro foram convertidos para concentração de azul de metileno, através da curva de calibração, utilizando a Equação 1:

$$
q t=\frac{\left(c_{o}-c_{t}\right) V}{W}
$$

$\mathrm{Na}$ qual, qt é a quantidade de corante adsorvido no tempo t, $c_{o}$ é a concentração inicial, $c_{t}$ é a concentração no tempo, $W$ é a massa de adsorvente e $V$ é o volume da solução. Os valores obtidos foram plotados em um gráfico em função do tempo. A Figura 1 ilustra essa análise para as soluções de 50 e 40 ppm.

Figura 1 - Adsorção do molibdato de estrôncio dopado com cobre $20 \%$ em diferentes concentrações do corante.

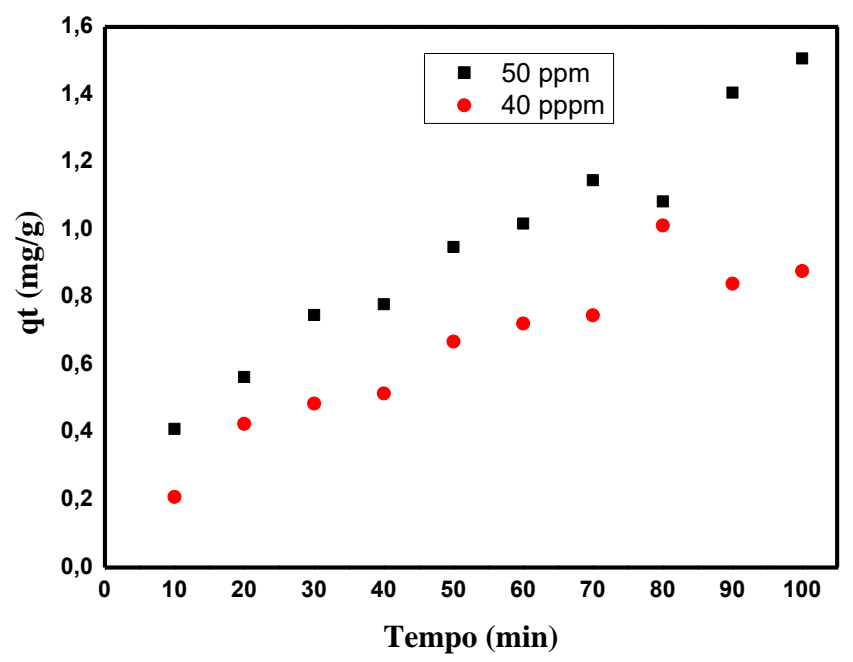

A partir das concentrações obtidas através da Equação 1, foi possível calcular a porcentagem de remoção do corante para cada uma das condições analisadas, sendo obtidos os valores de $18,9536 \%$ e $15,0872 \%$ para as concentrações iniciais de corante de 50 ppm e 40 ppm, respectivamente. Sendo assim, além de ter havido pouca remoção de azul de metileno nas duas condições, é observado que não há diferença significativa na remoção ao ser realizada a mudança na concentração inicial da solução de corante.

A quantidade de corante adsorvida no equilíbrio (qe) pôde então ser determinada através da análise das curvas obtidas. A partir destes dados, o estudo cinético foi iniciado com a aplicação de três modelos principais, nos dados obtidos, na tentativa de obter o mais adequado a esse processo de adsorção.

Utilizando a Equação 2, o primeiro modelo analisado foi o de pseudo-primeira ordem.

$$
\log (q e-q t)=\log (q e)-\frac{k \cdot t}{2,303}
$$


O segundo modelo analisado foi o de pseudo-segunda ordem, utilizando a Equação 3.

$$
\frac{t}{q}=\frac{1}{k \cdot q e^{2}}+\frac{t}{q e}
$$

O terceiro modelo analisado foi o de difusão intrapartícula, utilizando a Equação 4.

$$
q=k \sqrt{t}
$$

Nos quais, para todos os modelos apresentados, $q$ é quantidade de corante adsorvido por massa de adsorvente, $\mathrm{k}$ é a constante de velocidade, referente à taxa de adsorção, qe é a quantidade de corante adsorvida no equilíbrio e $t$, o tempo em minutos. Os resultados obtidos para o ajuste dos diferentes modelos estão apresentados nas Figuras 2, 3 e 4 respectivamente para o modelo de pseudo-primeira ordem, pseudo-segunda ordem e difusão intrapartícula.

Figura 2 - Aplicação do modelo de pseudo-primeira ordem.

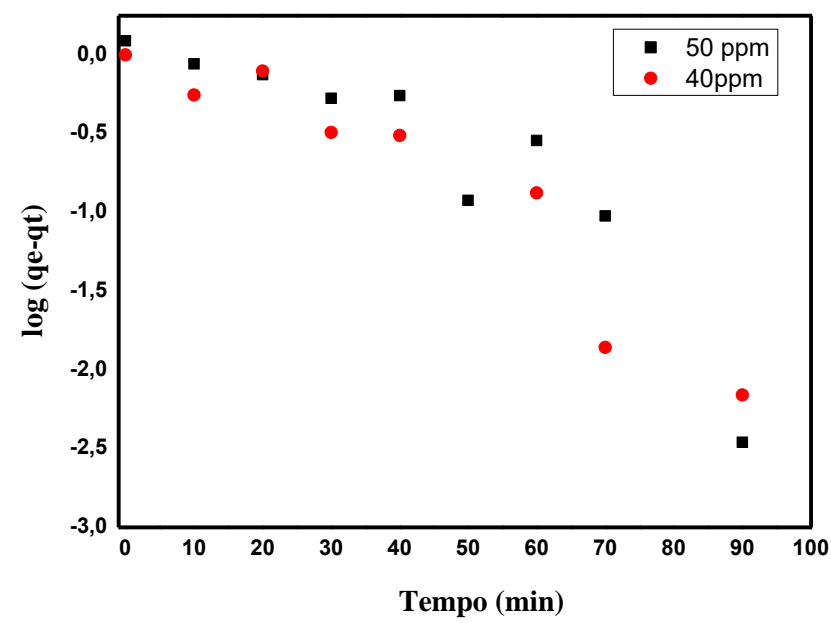

Figura 3 - Aplicação do modelo de pseudo-segunda ordem.

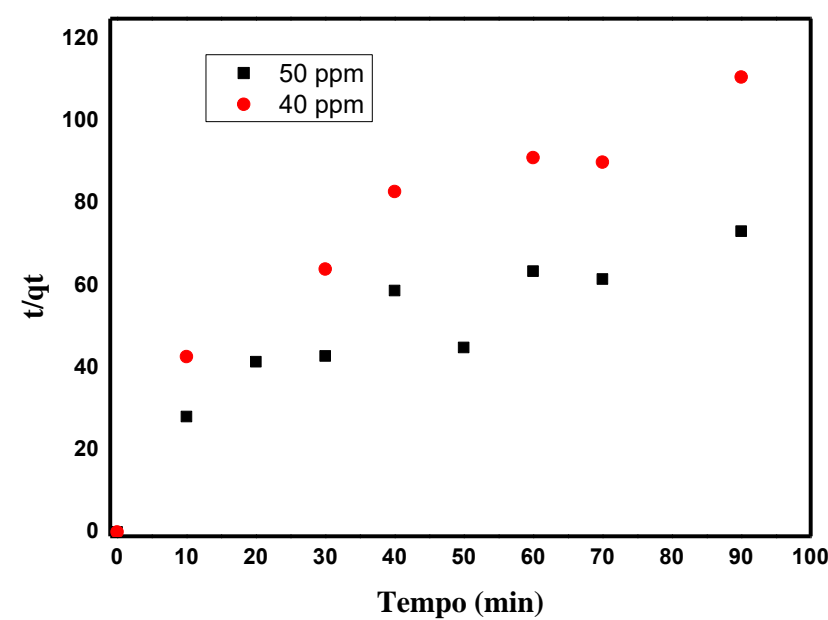


Figura 4 - Aplicação do modelo de difusão intrapartícula.

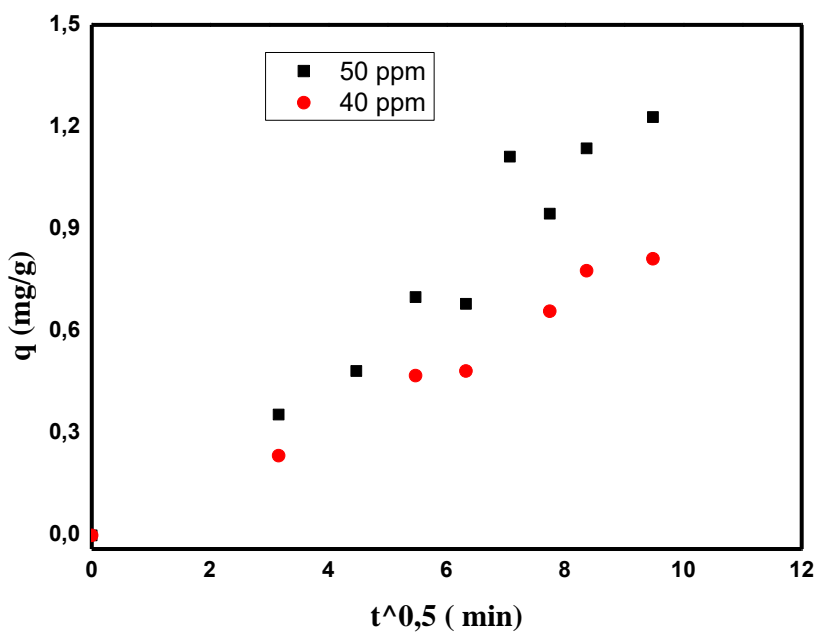

O parâmetro cinético (constante de velocidade, k) estimado por meio do ajuste dos modelos, assim como o $\mathrm{R}^{2}$ da estimativa são mostrados na Tabela 1.

Tabela 1 - Valores de k e $\mathrm{R}^{2}$ encontrados para todos os modelos.

\begin{tabular}{ccccccc}
\hline \multirow{2}{*}{ Soluções } & \multicolumn{2}{c}{ Pseudo-primeira ordem } & \multicolumn{2}{c}{ Pseudo-segunda ordem } & \multicolumn{2}{c}{ Difusão intrapartícula } \\
\cline { 2 - 7 } & $\mathrm{k}$ & $\mathrm{R}^{2}$ & $\mathrm{k}$ & $\mathrm{R}^{2}$ & $\mathrm{k}$ & $\mathrm{R}^{2}$ \\
\cline { 2 - 7 } $50 \mathrm{ppm}$ & 0,0548 & 0,7890 & 0,0692 & 0,8644 & 0,1365 & 0,9463 \\
$40 \mathrm{ppm}$ & 0,0514 & 0,8115 & 0,0362 & 0,8059 & 0,9853 & 0,9853 \\
\hline
\end{tabular}

De acordo com os valores de $\mathrm{R}^{2}$ expostos na Tabela 1 e a análise dos gráficos das Figuras 2, 3 e 4, o modelo de difusão intrapartícula se adequa melhor aos dados experimentais obtidos. Portanto, a partir da análise dos resultados obtidos e, segundo o modelo que melhor se aplica ao caso em estudo, as Equações 5 e 6 representam a cinética de adsorção do azul de metileno pelo molibdato de estrôncio dopado com $20 \%$ de cobre para as soluções a 50 e 40 ppm, respectivamente.

$$
\begin{aligned}
& q=0.1365 \sqrt{t} \\
& q=0.9853 \sqrt{t}
\end{aligned}
$$

O difratograma de raios-x apresentado na Figura 5 permitem afirmar que todos os picos de difração foram indexados de acordo com a ficha JCPDS 01-085-0586, típica de $\mathrm{SrMoO}_{4}$ com estrutura tetragonal do tipo scheelita e grupo espacial I41/a. Desta forma, a presença do cobre não causou distorções na rede cristalina do $\mathrm{SrMoO}_{4}$. 
Figura 5 - Difratograma de raios-X.

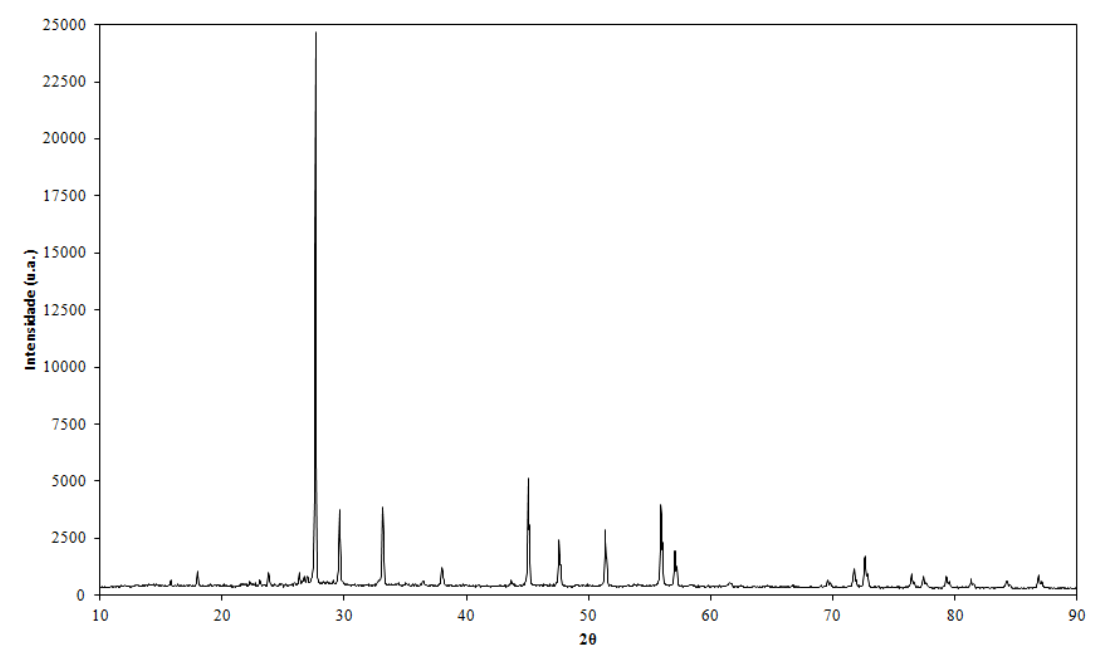

\section{CONCLUSÃO}

A análise comparativa entre as porcentagens de remoção de corante mostra que, além do material realizar pouca adsorção do corante nas duas concentrações, a mudança da concentração de corante de $50 \mathrm{ppm}$ para $40 \mathrm{ppm}$ não provoca alterações significativas na quantidade de azul de metileno adsorvido. Dentre modelos apresentados, considerando a natureza do processo experimental, o que melhor se adequa a ambas as condições de adsorção é o modelo de difusão intrapartícula, este apresentou os melhores valores de $\mathrm{R}^{2}$.

\section{REFERÊNCIAS}

DUTRA, F. B. Síntese e caracterização do molibdato de estrôncio dopado com cobre, cobalto e zinco para fins fotocatalíticos. Disponível em: http://monografias.ufrn.br/ jspui/handle/123456789/2288. Acesso em: 27 de março de 2017.

FILHO, G. M. R. Adsorção do corante amarelo reativo BF-4G 200\% por argila esmectita, Curso de Engenharia Química na UFRN. Disponível em: https://repositorio.ufrn.br/ jspui/bitstream/123456789/15835/1/GeraldoMRF_TESE.pdf. Acesso em: 27 de março de 2017.

SANTOS, A. P. L. e FERNANDES, D. S. Análise do impacto ambiental gerados no ciclo de vida de um tecido de malha. Iberoamerican jornal of industrial engeneering Florianópolis, SC, Brasil, v. 4, n. 7, p. 1-17, 2012.

SANTOS, S. Impacto ambiental causado pela indústria têxtil. Disponível em: http://www.abepro.org.br/biblioteca/ENEGEP1997_T6410.PDF. Acesso em: 27 de março de 2017.

SILVA, M. M. S. Síntese e caracterização do molibdato de estrôncio obtido a partir do Método de Complexação Combinado EDTA/Citrato para degradação fotocatalítica de corante na indústria têxtil. Disponível em: https://repositorio.ufrn.br/jspui/ handle/123456789/21877. Acesso em: 27 de março de 2017. 